\title{
SOLUÇÃO DO PROBLEMA OU PROBLEMA DA SOLUÇÃO? STF, CNJ E A JUDICIALIZAÇÃO DA SAÚDE ${ }^{1}$
}

\section{PROBLEM OR SOLUTION? THE ROLES OF THE BRAZILIAN SUPREME COURT AND THE NATIONAL COUNCIL OF JUSTICE IN HEALTH LITIGATION}

\author{
NATAlia Pires de VAsCONCELOS ${ }^{2}$
}

RESUMO: E O Supremo Tribunal Federal se tornou um ator incontornável na formulação e execução de políticas públicas. Uma das políticas sociais que mais envolve a Corte nesta função é a saúde pública. Acionado sobretudo como instância recursal, a Corte viu o volume de casos em saúde crescer de forma significativa nos últimos 20 anos. Ao longo deste período, sua jurisprudência e sua atuação institucional foram, ao mesmo tempo, uma resposta e uma causa deste crescimento. De um lado, em suas decisões, a Corte sustenta um posicionamento sistematicamente favorável a demandas individuais, decidindo pelo provimento de demandas que requerem medicamentos, insumos e tratamentos mesmo quando experimentais ou fora das listas e protocolos clínicos do SUS. De outro lado, esta posição coexiste com a atuação estrutural do Conselho Nacional de Justiça, que não só criou comitês interdisciplinares para reduzir e qualificar a judicialização da saúde, mas passou a monitorar a atuação de juízes e tribunais e exigir que decisões judiciais incorporassem justificativas técnicas. Neste artigo, sustento que compreender esta atuação contraditória da Corte, e suas limitações, é um passo imprescindível para entender a judicialização da saúde como um todo. Ora como "parte do problema", ora como "gestora" da sua "solução", o STF ocupa uma posição única que lhe permite desenhar grande parte dos incentivos institucionais que fundamentam as decisões das demais instâncias do Judiciário. Se a Corte, contudo, não aponta um caminho claro, ela perde a oportunidade de afetar e controlar o fenômeno ou de potencialmente contribuir para a construção de uma política de saúde mais eficiente e justa.

Palavras-Chave: STF, Judicialização, Saúde, Políticas Públicas.

\footnotetext{
${ }^{1}$ A versão final deste artigo contou com os comentários e revisão de membros e membras do grupo de estudo e pesquisa Judiciário e Democracia (JUDE), a quem dedico esta nota de agradecimento. Especificamente agradeço a Diego Werneck Arguelhes, Rogerio Arantes, Jeferson Mariano Silva, Cassio Oliveira, Rebeca Degenszajn e Carla Vitória.

2 Doutora em Direito pela Universidade de São Paulo (2018). Curriculum lattes em: http://lattes.cnpq.br/1609040731612877. Contato: nataliaPV1@insper.edu.br.
} 
Abstract: The Federal Supreme Court has become an indispensable actor in the formulation and execution of public policies. One of the social policies that most involves the Court in this function is public health. Especially as a court of appeal, the Court has seen the volume of health cases grow significantly in the last 20 years. Throughout this period, its jurisprudence and its institutional performance were at the same time a response to and a cause for this growth. On the one hand, the Court has not been sensitive to larger policy arguments when it systematically favors individual demands requiring the provision of medicines, supplies, and treatments. On the other hand, through its control of the National Council of Justice, the Court has been more sensitive to the structural considerations that underlie any individual case. The Council not only created interdisciplinary committees to reduce and qualify the "judicialization" of health, but also monitored the performance of judges and lowers courts. Moreover, it has increasingly required that judicial decisions incorporate policy justifications into their reasonings. In this article, I argue that understanding the Court's contradictory positioning is an essential step in the process of understanding the phenomenon of the "judicialization of health" in Brazil. Either as "part of the problem" or as a "manager" of the problem's "solution", the Court holds the unique position of possibly setting large parts of the institutional incentives that underpin the decisions of other judicial bodies in the country. However, if the Court is incapable of guiding judges and lower Courts towards a clear argumentative path, it loses the opportunity to affect and control the phenomenon and to potentially contribute to the construction of a more efficient and fair health policy.

KeYwords: Brazilian Federal Supreme Court, Public Health, Judicialization of Health.

\section{INTRODUÇÃo}

O Supremo Tribunal Federal se tornou um ator incontornável na formulação e execução de políticas públicas. Esta afirmação, que já faz parte do acervo de problemas de pesquisa consagrados por analistas da Corte $^{3}$ merece especial atenção em um volume que se volta ao STF para além da conjuntura. Políticas de todas as formas e temas chegam ao tribunal pela via difusa e/ou concentrada e elevam o STF a posição de arbitro das escolhas distributivas e redistributivas do governo. Da política tributária à definição de critérios para o acesso a benefícios assistenciais, as decisões da Corte interferem tanto na definição das receitas disponíveis quanto dos gastos possíveis. Uma das políticas sociais que mais envolve o tribunal nesta função é a saúde pública.

${ }^{3}$ Conferir, por exemplo, Taylor (2007), Oliveira e Marchetti (2013). 
O Judiciário brasileiro como um todo é acionado intensamente para garantir o direito constitucional à saúde. $\mathrm{O}$ fenômeno, comumente conhecido como "judicialização da saúde", é marcado pelo uso de ações individuais contra o Sistema Único de Saúde (SUS) requerendo medicamentos e tratamentos que ora não se encontram previstos pela política, ou cuja oferta enfrenta entraves administrativos ou ineficiências da política estabelecida. Apesar de ser um fenômeno de proporções globais, presente tanto em países do sul quanto do norte global e em Cortes internacionais (GLOPPEN; ROSEMAN, 2011, p. 1-16), ele assume no Brasil proporções de litígio de massa $\left({ }^{4}\right.$, envolvendo todas as instâncias do Judiciário, de Cortes superiores a juízes de varas da fazenda pública, em âmbito estadual e federal.

De acordo com o Tribunal de Contas da União, por exemplo, apenas a União Federal teria gastado cerca de 1 bilhão de reais em 2015, em torno de $1 \%$ dos gastos realizados pelo ente com saúde naquele ano, com o cumprimento de decisões judiciais (BRASIL, 2017a). Este cenário seria ainda proporcionalmente mais grave para Estados e Municípios, que tendem a figurar no polo passivo de um número ainda maior de ações judiciais sobre o tema e a receber proporcionalmente menos recursos para a política de saúde. Os Estados de São Paulo, Santa Catarina, Rio de Janeiro e Rio Grande do Sul, marcados pelo alto volume de demandas judiciais contra suas secretarias estaduais de saúde, registram ter despendido no mesmo ano de 2015 de $1 \%$ a $8 \%$ de seus orçamentos executados em saúde com o cumprimento de decisões judiciais (VASCONCELOS, 2018).

Ainda que exista relevante variação regional sobre o perfil da judicialização entre diferentes Estados, o que afeta a forma de representação jurídica dos litigantes (se advogados privados ou defensores), e o tipo de pedido mais comumente trazido ás Cortes (medicamentos, insumos, serviços médicos dentro e fora da política pública), em geral, a literatura e as pesquisas recentes sobre o tema confirmam que a judicialização predominantemente envolve demandas individuas que requerem medicamentos, em sua maioria fora das listas oficiais ou fora dos protocolos clínicos estabelecidos pela política de assistência farmacêutica ${ }^{5}$.

Um traço comum à vasta maioria destes pedidos é o seu resultado: quase todos são concedidos por juízes e tribunais, em todas as instâncias, a partir de argumentos que se concentram, sobretudo, na previsão constitucional de um direito fundamental à saúde. Estas decisões judiciais são garantidas pela aplicação ou ameaça de aplicação de sanções fortes ou por meio de mecanismos de garantia da tutela que envolvem bloqueio, sequestro de valores e busca e apreensão. Além dos custos envolvidos com o cumprimento destas decisões, a judicialização também afeta a organização do SUS e sua divisão de competências, já que litigantes podem

\footnotetext{
${ }^{4}$ Apenas encontradas de forma similar nos padrões de judicialização da Colômbia. Cf. Yamin, ParraVera e Gianella (2011, p. 103) e Lamprea Montealegre (2015).

${ }^{5}$ Para mais detalhes sobre esta variação, conferir Brasil (2019a).
} 
processar qualquer instância da federação, mesmo aquelas não competentes para o provimento de um determinado serviço Wang et al. (2014).

Custo e organização da política parecem variáveis não relevantes em comparação com a proteção de um direito humano e fundamental como a saúde. Cabe lembrar, contudo, que o SUS é uma política universal e gratuita que se organiza para prover saúde em todo o país, a todos os cidadãos. Em um cenário de crônico subfinanciamento do SUS e de declínio dos gastos públicos com saúde (PIOLA; PAIVA; SERVO, 2013; MARQUES, 2017), decisões judiciais que afetam quem provê e quem recebe os serviços de saúde podem importar em impactos regressivos sobre a política. Estas decisões potencialmente redirecionam recursos de dotações planejadas de acordo com necessidades de saúde coletiva, para o cumprimento de decisões judiciais que atendem quem consegue chegar às Cortes, premiando, em geral, pretensões de saúde individual determinadas pelo médico prescritor.

Junto com as demais Cortes do país, o STF também recebe e atua em casos que envolvem demandas de saúde (WANG, 2015; 2009). Acionado sobretudo como instância recursal, o tribunal viu o volume de casos em saúde crescer de forma significativa nos últimos 20 anos. Ao longo deste período, sua jurisprudência foi ao mesmo tempo uma resposta e uma causa deste crescimento. Partindo de uma leitura abrangente do direito à saúde, que compreenderia tudo o que fizesse parte da prescrição médica, o tribunal brevemente explorou uma fase de deferência às escolhas do SUS e maior controle do que seria concedido judicialmente. Esta fase, caracterizada sobretudo por decisões da então presidente do STF - Ellen Gracie foi logo abandonada em 2007, quando a Corte voltou a adotar entendimento semelhante à sua postura inicial: o direito à saúde, como direito fundamental, deve ser garantido a despeito de qualquer interesse "secundário" do Estado, tais como a organização federativa de competências do SUS ou a disponibilidade de recursos, que não podem ser entraves a garantia da saúde. Ademais, o tribunal assumiria uma postura "individualizante" da saúde pública, que se tornaria um conceito definido caso a caso na fase de instrução probatória das ações individuais e determinado pela necessidade do paciente, aferida pelo médico. Como matéria de prova, contudo, este seria tópico definido fora do STF, nas Cortes e juízes a quo.

Este entendimento sofreu poucas mudanças, mesmo após a audiência pública de 2009 organizada pelo então presidente da Corte, ministro Gilmar Mendes, que teve o objetivo de qualificar a atuação de juízes e tribunais e conter o fenômeno. $\mathrm{O}$ resultado da audiência, um "teste" argumentativo que teria o condão de restringir a atuação de juízes a quo, surtiu pouco efeito sobre o volume de decisões judiciais contrárias ao SUS. Não possuímos dados empíricos sobre o quanto e como tribunais a quo referem-se a decisões do STF, ou mesmo uma sistematização da jurisprudência do tribunal após 2009 em relação à saúde. O que se sabe, contudo, é que a iniciativa do STF não preveniu novas ações judiciais - cujo crescimento ano a ano supera os 100\% (BRASIL, 2019a). Não somente, decisões-chave da Corte, 
anteriores a audiência de 2009, continuam sendo citadas pelo próprio tribunal para garantir o provimento de pedidos contra o SUS.

O posicionamento sistematicamente favorável do STF às demandas individuais coexiste com uma atuação mais estrutural da Corte, que procura gerir a judicialização por meio do Conselho Nacional de Justiça. Como veremos, após a audiência pública de 2009, o CNJ (BRASIL, 2016a) passou a exigir que todos os tribunais não só criassem espaços de discussão interinstitucional da política de saúde, mas especializassem varas e juízes. Uma das iniciativas mais abrangentes, ademais, foi a exigência de que todos os Estados tivessem a sua disposição núcleos de assessoramento técnico de juízes que hoje atuam de forma integrada e informatizada através do e-NATJUS6.

Compreender a judicialização da saúde no Brasil, assim, passa necessariamente pelo processo de entender esta posição aparentemente contraditória do STF. Este artigo busca de forma suscinta descrever esta contradição. Na primeira parte, discuto a posição do tribunal em entendimento favorável à profusão de demandas individuais, recorrendo tanto a caminhos formais para evitar debruçar-se sobre a política e suas escolhas estruturais, quanto a uma interpretação "individualizante" do direito à saúde e da noção de saúde pública. Esta posição do STF como "parte do problema" da judicialização, contrasta com a atuação do tribunal como "gestora" da judicialização da saúde que ajuda a criar. Na segunda parte do artigo, discuto como o CNJ vem formulando verdadeiras políticas públicas que vão desde o treinamento de juízes à construção de fóruns multidisciplinares e interinstitucionais, onde discute amplamente não só a gestão da judicialização da saúde, mas outras pautas relevantes ao SUS. Uma breve conclusão, na terceira seção, apresenta as duas partes conjuntamente e expõe suas conexões e contradições.

\section{STF COMO CAUSA DO PROBLEMA}

Até 2009, a jurisprudência do STF em matéria de saúde pública foi predominantemente favorável a demandas individuais. Acionado como instância recursal, sobretudo por autoridades públicas contestando sentenças e acórdãos contrários ao SUS, o STF até 2007 decidiu à unanimidade pelo fornecimento de medicamentos e insumos de saúde judicialmente. Como conclui Wang (2009) a partir de uma pesquisa empírica abrangente sobre todas as decisões da Corte em matéria de saúde de 2000 a 2007, a disponibilidade de recursos financeiros é vista como um "interesse secundário do Estado" que não pode restringir o direito fundamental a saúde na pretensão individual apresentada ao tribunal ${ }^{7}$.

6 Confira mais sobre o e-natjus em sua página online disponibilizada pelo $\mathrm{CNJ}$ em http://www.cnj.jus.br/programas-e-acoes/forum-da-saude/e-natjus.

${ }^{7}$ Conferir, por exemplo, Petição 1246 MC DE relatoria do min. Celso de Melo (BRASIL, 1997): “Entre proteger a inviolabilidade do direito à vida, que se qualifica como direito subjetivo inalienável 
Em 2007, decisões da Ministra Ellen Gracie, então presidente da Corte, pareciam inaugurar uma nova posição da Corte, mais confortável em proferir decisões sobre a política de saúde que enxergassem o impacto estrutural e coletivo da Corte quando decidindo ações individuais.

Verifico estar devidamente configurada a lesão à ordem pública, considerada em termos de ordem administrativa, porquanto a execução de decisões como a ora impugnada afeta o já abalado sistema público de saúde. Com efeito, a gestão da política nacional de saúde, que é feita de forma regionalizada, busca uma maior racionalização entre o custo e o benefício dos tratamentos que devem ser fornecidos gratuitamente, a fim de atingir o maior número possível de beneficiários. Entendo que a norma do art. 196 da Constituição da República, que assegura o direito à saúde, refere-se, em princípio, à efetivação de políticas públicas que alcancem a população como um todo, assegurando-lhe acesso universal e igualitário, e não a situações individualizadas. A responsabilidade do Estado em fornecer os recursos necessários à reabilitação da saúde de seus cidadãos não pode vir a inviabilizar o sistema público de saúde (BRASIL, 2007a). ${ }^{8}$

Este posicionamento, contudo, foi abandonado no mesmo ano por decisões proferidas por outros ministros e pela própria ministra Ellen Gracie, reiterando a posição anterior da Corte que dava provimento às demandas individuais sem considerações sobre a possível interferência regressiva que a judicialização poderia gerar sobre a alocação de recursos do SUS (WANG, 2009). Até 2009, a Corte sistematicamente decidiria que o direito constitucional a saúde importaria na

assegurado pela própria Constituição da República (art. $5^{\circ}$, caput), ou fazer prevalecer, contra essa prerrogativa fundamental, um interesse financeiro e secundário do Estado, entendo - uma vez configurado esse dilema - que razões de ordem tico-jurídica impõem ao julgador uma só e possível opção: o respeito indeclinável à vida.". Ou ainda, em um dos casos mais citados desta fase, a Medida Cautelar na ADPF 45 (BRASIL, 2004) : “Não se mostrará lícito, no entanto, ao Poder Público, em tal hipótese - mediante indevida manipulação de sua atividade financeira e/ou político-administrativa - criar obstáculo artificial que revele o ilegítimo, arbitrário e censurável propósito de fraudar, de frustrar e de inviabilizar o estabelecimento e a preservação, em favor da pessoa e dos cidadãos, de condições materiais mínimas de existência. Cumpre advertir, desse modo, que a cláusula da "reserva do possível" - ressalvada a ocorrência de justo motivo objetivamente aferível - não pode ser invocada, pelo Estado, com a finalidade de exonerar-se do cumprimento de suas obrigações constitucionais, notadamente quando, dessa conduta governamental negativa, puder resultar nulificação ou, até mesmo, aniquilação de direitos constitucionais impregnados de um sentido de essencial fundamentalidade".

${ }^{8}$ Conferir, também, decisões semelhantes do Supremo Tribunal Federal, de acordo com Wang (2009) nos casos Brasil (2007b; 2007c). 
solidariedade entre os entes federados para figurarem indistintamente no polo passivo das ações ${ }^{9}$, na legitimidade do Ministério Público para propor ações individuais requerendo medicamentos e insumos ${ }^{10}$, e na possibilidade de imposição de multas e bloqueios de valores contra entes públicos para garantir a prestação individual ${ }^{11}$.

Para não tornar o direito a saúde mera norma programática, a Corte entenderia ser sua obrigação efetivar as pretensões individuais em apreço como um direito público subjetivo ${ }^{12}$, sem considerar que o direito à saúde já era e é efetivado por uma política ampla e consolidada. Aplicar diretamente a Constituição à ação individual, para o STF, não exigiria qualquer deferência ao que o SUS já havia organizado como forma de efetivação do direito à saúde.

\section{Audiência pública da saúde e repercussão geral}

Em 2009 já havia se formado uma percepção relativamente consolidada em meio a comunidade acadêmica e jurídica sobre os problemas da judicialização da saúde. Do alto volume de novas ações judiciais propostas todos os anos à profusão de decisões judiciais desfavoráveis ao SUS em todas as instâncias, críticos do que veio se consolidar como "a judicialização da saúde" apontavam já o STF como um possível causador do problema com sua jurisprudência pouco deferente ao SUS e, de igual modo, a instância que poderia solucionar a judicialização ${ }^{13}$. Neste contexto se dá a audiência pública de 2009.

Com o intuito de "ouvir o depoimento de pessoas com experiência e autoridade em matéria do Sistema Único de Saúde, objetivando esclarecer as questões técnicas, científicas, administrativas, políticas, econômicas e jurídicas relativas às ações de prestação de saúde: Sistema Único de Saúde - SUS"14, o ministro Gilmar Mendes convidou 37 especialistas sobre o tema da saúde pública, além de contar com amplo material enviado pela sociedade civil e academia, no que veio a ser a primeira audiência pública da história do STF.

\footnotetext{
${ }^{9}$ Por exemplo, Brasil (2008a; 2007d).

${ }^{10}$ Por exemplo, Brasil (2008b; 2008c; 2008d).

${ }^{11}$ Por exemplo, Brasil (2008i; 2008j).

12 Por exemplo, Brasil (2008g) ou Brasil (2008h).

${ }^{13}$ Cf. Chieffi e Barata (2009), Ferraz (2009), Ferraz e Vieira (2009) e Ferreira (2005).

${ }^{14}$ Min. Gilmar Mendes, (BRASIL, 2009). Esta foi a quarta audiência pública realizada pela Corte. O regimento interno do STF confere poder discricionário de convocar a audiência ao presidente da Corte ou ao relator do caso. As audiências devem ser públicas, convocadas com a finalidade de instruir o processo de informações "técnicas" por meio da oitiva do "depoimento de pessoas com experiência e autoridade em determinada matéria". Aberta a convocação, pessoas que preenchem este critério deverão ser "indicadas", representando "diversas correntes de opinião" sobre o assunto. $\mathrm{O}$ ministro que convoca a audiência também a preside, assim como seleciona e divulga a lista dos habilitados. Também cabe a ele determinar "a ordem dos trabalhos", o "tempo que cada um disporá para se manifestar", manifestações estas que deverão "limitar-se ao tema ou questão em debate".
} 
Criando à improviso as normas que regeriam a audiência, o ministro não só decidiu quem estaria ou não "habilitado" a se pronunciar publicamente nos 6 dias da audiência (27, 28 e 29 de abril e 4, 6 e 7 de maio de 2009), mas determinou que temas gerais e que especialistas se encaixavam em cada tema: responsabilidade dos entes da federação e financiamento do SUS; gestão do SUS - legislação do SUS e universalidade do sistema; registro na ANVISA e protocolos e diretrizes terapêuticas do SUS; políticas públicas de saúde - integralidade do sistema; assistência farmacêutica do SUS. A maior parte dos expositores selecionados pertencia ou a gestão da saúde federal ou eram operadores do direito, o que explica certa prevalência de posições críticas em relação à judicialização.

Estas posições resultaram em um conjunto de pontos levantados pelos expositores para contornar o fenômeno, dentre eles, com maior prevalência nas falas: (i) "Aprimoramento da atuação das instâncias regulatórias no Brasil: ANVISA (registro) e CITEC (incorporação ao SUS)"; (ii) "O Judiciário deve levar em consideração os protocolos clínicos e diretrizes terapêuticas do Ministério da Saúde, os quais devem ser atualizados periodicamente e com maior participação de instituições afins"; (iii) "Fornecer assessoria técnica ao Judiciário"; (iv) "Regulamentação da Emenda Constitucional no 29"; (v) "Uso de evidência científica na tomada de decisão de políticas públicas.; (vi)“Primeiro solicitar administrativamente para, em última instância, recorrer à via judicial quando não há risco iminente de morte, evitando a banalização das ações judiciais em saúde"; (vii) "Descentralização e definição de atribuições de cada ente federativo na saúde"; (viii) "Buscar formas de reduzir os custos do tratamento, utilizando medicamentos com patente expirada, genéricos ou similares que apresentem o mesmo componente ativo ou ainda pela Licença Compulsória"; (ix) "A criação de uma central única informatizada para recebimento de mandados judiciais, evitando o cumprimento em duplicidade de medidas judiciais em tecnologias em saúde criação de núcleo de inteligência vinculado à Secretaria de Saúde que monitore todas as atividades que envolvam prescrições de medicamentos"; (x) "Diálogo permanente entre o Poder Judiciário e o Poder Executivo em relação à saúde. Por exemplo, a criação de câmaras prévias de conciliação"; "Melhorar as políticas de gestão e de medicamentos para solucionar as causas do desabastecimento de medicamentos" 15 .

Os pontos registrados na audiência geraram o que Wang (2015) identifica como um teste argumentativo a ser conduzido por juízes e tribunais para determinar o que indivíduos poderiam exigir do SUS judicialmente. Neste teste, juízes e tribunais deveriam apenas deferir pedidos de medicamentos e tratamentos que estivessem sido incorporados pelos SUS; ou que, mesmo não incorporados, tivessem sido aprovados pela ANVISA e fossem alternativas para doenças não tratadas adequadamente pelo SUS, além de disponíveis no mercado há muito tempo. O teste ficou consagrado na STA-175, também de relatoria do ministro

${ }^{15}$ A sistematização destes pontos foi extraída de Gomes et al. (2014). 
Gilmar Mendes. Nesta ação de suspensão de tutela antecipada a principal tese fixada estabelece que "[...] em geral, deverá ser privilegiado o tratamento fornecido pelo SUS em detrimento de opção diversa escolhida pelo paciente, sempre que não for comprovada a ineficácia ou a impropriedade da política de saúde existente. Essa conclusão não afasta, contudo, a possibilidade de o Poder Judiciário, ou de a própria Administração, decidir que medida diferente da custeada pelo SUS deve ser fornecida a determinada pessoa que, por razões específicas do seu organismo, comprove que o tratamento fornecido não é eficaz no seu caso" (BRASIL, 2010).

Tanto os pontos levantados na audiência quanto o teste mencionado, contudo, tiveram aparente baixo impacto sobre as próprias decisões do STF que se seguiram (WANG, 2015; SANTOS; DELDUQUE; MENDONÇA, 2015). Wang (2015) argumenta que o teste em si - e também a tese fixada no STA 175 - deixa a critério dos juízes identificar o que é "adequado" ou não, diante da oferta de tratamentos já disponível e, no caso de tratamento não incorporado, é decisão que juízes e tribunais tendem a deferir ao médico pessoal do demandante. Ademais, tratamentos "adequados" podem, ainda assim, não ser custo-efetivos, de modo que mesmo individualmente passíveis de acrescentar algum aumento marginal de bem-estar, não seriam aprovados em uma avaliação geral do que a política deve ou não prover, dados os recursos disponíveis e os objetivos gerais de saúde pública que se pretende perseguir.

Uma pesquisa simples sobre as decisões que citaram a audiência pública, ainda, indica que a STA-175 foi utilizada poucas vezes contra a pretensão de demandantes. Das 20 decisões monocráticas em ações de saúde em que é citada, apenas 4 decisões são favoráveis a administração pública ${ }^{16}$. O posicionamento predominante atesta que:

O recurso não deve ser admitido, tendo em vista que o acórdão recorrido está alinhado ao entendimento do Supremo Tribunal Federal. Em primeiro lugar, esta Corte assentou que, apesar do caráter meramente programático atribuído ao art. 196 da Constituição Federal, o Estado não pode se eximir do dever de propiciar os meios necessários ao gozo do direito à saúde dos cidadãos. (...) Em segundo lugar, esta Corte tem se orientado no sentido de ser possível ao Judiciário a determinação de fornecimento de medicamento não incluído na lista padronizada fornecida pelo SUS, desde que reste comprovado que não haja nela opção de tratamento eficaz para a enfermidade. Nesse sentido, vale citar trecho do voto do Ministro Gilmar Mendes, na STA 175- AgR (...) Em terceiro lugar, verifica-se que o acordão recorrido também está alinhado à jurisprudência do Supremo Tribunal Federal no sentido de que constitui obrigação solidária dos entes federativos o

${ }^{16}$ Conferir pesquisa de jurisprudência junto ao STF, com os termos "STA adj 175". 
dever de fornecimento gratuito de tratamentos e de medicamentos necessários à saúde de pessoas hipossuficientes. Assim, infere-se que o Estado é parte legítima para figurar no polo passivo de ações voltadas a esse fim, independentemente de eventual inserção dos demais entes federativos como litisconsortes passivos da demanda. (...) Em quarto lugar, é entendimento do Supremo Tribunal Federal que cumpre aos entes federativos o papel de destinar recursos orçamentários que garantam a implementação de políticas públicas de saúde." (BRASIL, 2016b)

Promover o bem estar de todos é obrigação constitucional do Estado, incluindo-se a saúde. O laudo acostado aos autos comprova a patologia da parte autora. Pouco importa que o medicamento/insumo/tratamento não faça parte a lista do SUS, diante da obrigação estatal em disponibilizar todos os meios para garantia do direito constitucional à saúde. É alegação repetitiva e enfadonha a matéria relativa à 'reserva do possível', que, no Brasil, ganhou uma vertente orçamentária, isto é, sempre que a Administração Pública quer se eximir de suas obrigações argumenta não haver recursos em seus cofres. No entanto, é estranho que ano após ano o orçamento não seja dotado de recursos para saúde a fim de equacionar esse déficit com o cidadão. (BRASIL, 2019b) $^{17}$

Outra noção que parece prevalecer nos julgados recentes da Corte em matéria de saúde é a da impossibilidade de reavaliação de matéria de prova no âmbito de uma controvérsia constitucional, o que impediria o STF de avaliar os recursos propostos especialmente pelas autoridades públicas. A extensão deste argumento

17 Este é, contudo, um dos quatro casos em que o relator deferiu o recurso do ente público e determinou que o juízo a quo realizasse outro julgamento, levando em conta o que é ofertado no SUS. Todo o trecho, contudo, é no mínimo contraditório, do que se extrai esta interessante máxima: "pouco importa o que é ofertado, mas juízes devem considerar o que é ofertado". Confira: "O laudo acostado aos autos comprova a patologia da parte autora. Pouco importa que o medicamento/insumo/tratamento não faça parte a lista do SUS, diante da obrigação estatal em disponibilizar todos os meios para garantia do direito constitucional à saúde. (...) No entanto, é estranho que ano após ano o orçamento não seja dotado de recursos para saúde a fim de equacionar esse déficit com o cidadão" (...) Evidencia-se, portanto, que as alegações do réu, ora recorrente, quanto à disponibilidade na rede de saúde de medicamentos aptos ao tratamento da autora, ora recorrida, foram desconsideradas pelos julgadores, que entenderam ter a norma constitucional garantido qualquer reivindicação, a qualquer custo, para concretizar o direito à saúde." (BRASIL, 2019b). 
e sua variação por ministro após a audiência de 2009, contudo, merece teste empírico.

Ademais, o Tribunal de origem solucionou a controvérsia com base nos fatos e provas constantes dos autos. A propósito, veja-se cabeçalho de ementa do acórdão recorrido (Vol. 2, fl. 105): “ADMINISTRATIVO E CONSTITUCIONAL. PRESTAÇÃO DE ASSISTÊNCIA FARMACOLÓGICA. CARÊNCIA DE RECURSOS DO PARTICULAR. DIREITO FUNDAMENTAL. DEVER DO ESTADO. AQUISIÇÃO. ÓBICE. AUSÊNCIA DE REGISTRO DO PRODUTO NA ANVISA. RESSALVA. DOENÇA GRAVE E RARA. RISCO DE MORTE. INEXISTÊNCIA DE TRATAMENTO ALTERNATIVO MAIS EFICAZ. FARTA COMPROVAÇÃO MÉDICA. INAÇÃO DO ADMINISTRADOR ESPECTADOR DO SOFRIMENTO E MORTE DO ADMINISTRADO. CONTRASENSO. PRESERVAÇÃO DA VIDA HUMANA. DISPENSAÇÃO CONTINUADA DO FÁRMACO, CONFORME PRESCRIÇÃO MÉDICA". Verifica-se, portanto, que a argumentação recursal traz versão dos fatos diversa da exposta no acórdão, de modo que o acolhimento do recurso passa necessariamente pela revisão das provas. Incide, portanto, o óbice da Súmula 279 desta CORTE: Para simples reexame de prova não cabe recurso extraordinário." (BRASIL, 2018a) $)^{18}$

O conjunto destas posições, ainda muito favorável a pretensões individuais, pode explicar a profusão de recursos extraordinários questionando matéria de saúde pública e sobrestados em incidentes de repercussão geral, como pode ser visto na tabela a seguir.

Tabela 1: Temas com Repercussão Geral reconhecida pelo STF - Saúde Pública

\begin{tabular}{lccc}
\hline & NÚMERO DE & DECISÃO \\
TEMA & TÍTULO DO TEMA & RECURSOS \\
& & SOBRESTADOS
\end{tabular}

\begin{tabular}{ll}
\hline \multicolumn{2}{c}{ Dever do Estado de } \\
fornecer medicamento de \\
alto custo a portador de \\
doença grave que não \\
possui condições \\
financeiras para comprá-lo.
\end{tabular}

${ }^{18}$ E no mesmo sentido, ver também Brasil (2018b; 2017b). Ademais, tal como antes da audiência pública, ainda prevalece o entendimento de solidariedade entre entes da federação no que tange o direito à saúde. Conferir Brasil (2013). 


\section{TEMA TÍTULO DO TEMA \\ NÚMERO DE DECISÃO \\ RECURSOS \\ SOBRESTADOS}

\begin{tabular}{|c|c|c|c|}
\hline & Legitimidade do Ministério & & \\
\hline 262 & $\begin{array}{l}\text { Público para ajuizar ação } \\
\text { civil pública que tem por } \\
\text { objetivo compelir entes } \\
\text { federados a entregar } \\
\text { medicamentos a portadores } \\
\text { de certas doenças. }\end{array}$ & 1755 & $\begin{array}{l}\text { Tese: O Ministério Público é parte } \\
\text { legítima para ajuizamento de ação } \\
\text { civil pública que vise o } \\
\text { fornecimento de remédios a } \\
\text { portadores de certa doença. }\end{array}$ \\
\hline
\end{tabular}

289

Bloqueio de verbas públicas para garantia de fornecimento de

Sem decisão. medicamentos.

Ressarcimento ao Sistema Único de Saúde - SUS das

345 despesas com atendimento a beneficiários de planos privados de saúde.
Dever do Estado de fornecer medicamento não registrado pela ANVISA.
1379

Tese: É constitucional o ressarcimento previsto no art. 32 da Lei 9.656/98, o qual é aplicável aos procedimentos médicos, hospitalares ou ambulatoriais custeados pelo SUS e posteriores a 4/6/1998, assegurados o contraditório e a ampla defesa, no âmbito administrativo, em todos os

Tese: 1. O Estado não pode ser obrigado a fornecer medicamentos experimentais. 2. A ausência de registro na ANVISA impede, como regra geral, o fornecimento de medicamento por decisão judicial. 3. É possível, excepcionalmente, a concessão judicial de medicamento sem registro sanitário, em caso de mora irrazoável da ANVISA em apreciar o pedido (prazo superior ao previsto na Lei $\mathrm{n}^{\mathrm{o}} 13.411 / 2016$ ), quando preenchidos três requisitos: (i) a existência de pedido de registro do medicamento no Brasil (salvo no caso de medicamentos órfãos para doenças raras e ultrarraras);(ii) a existência de registro do medicamento em renomadas agências de regulação no exterior; e (iii) a inexistência de substituto 
terapêutico com registro no Brasil. 4 .

As ações que demandem

fornecimento de medicamentos sem registro na ANVISA deverão necessariamente ser propostas em face da União.

\section{Limites do Poder Judiciário para determinar obrigações de fazer ao Estado, consistentes na realização de concursos públicos, \\ 698 contratação de servidores e execução de obras que atendam o direito social da saúde, ao qual a Constituição da República garante especial proteção.}

Responsabilidade solidária dos entes federados pelo dever de prestar assistência à saúde.
Sem decisão.

Tese: Os entes da federação, em decorrência da competência comum, são solidariamente responsáveis nas demandas prestacionais na área da saúde, e diante dos critérios constitucionais de descentralização e hierarquização, compete à autoridade judicial direcionar o cumprimento conforme as regras de repartição de competências e determinar o ressarcimento a quem suportou o ônus financeiro.

\section{Controle judicial relativo} ao descumprimento da obrigação dos entes federados na aplicação dos recursos orçamentários mínimos na área da saúde, Sem decisão. antes da edição da lei complementar referida no art. 198, § $3^{\circ}$, da Constituição.

Conflito entre a liberdade religiosa e o dever do Estado de assegurar Sem decisão. prestações de saúde universais e igualitárias. 


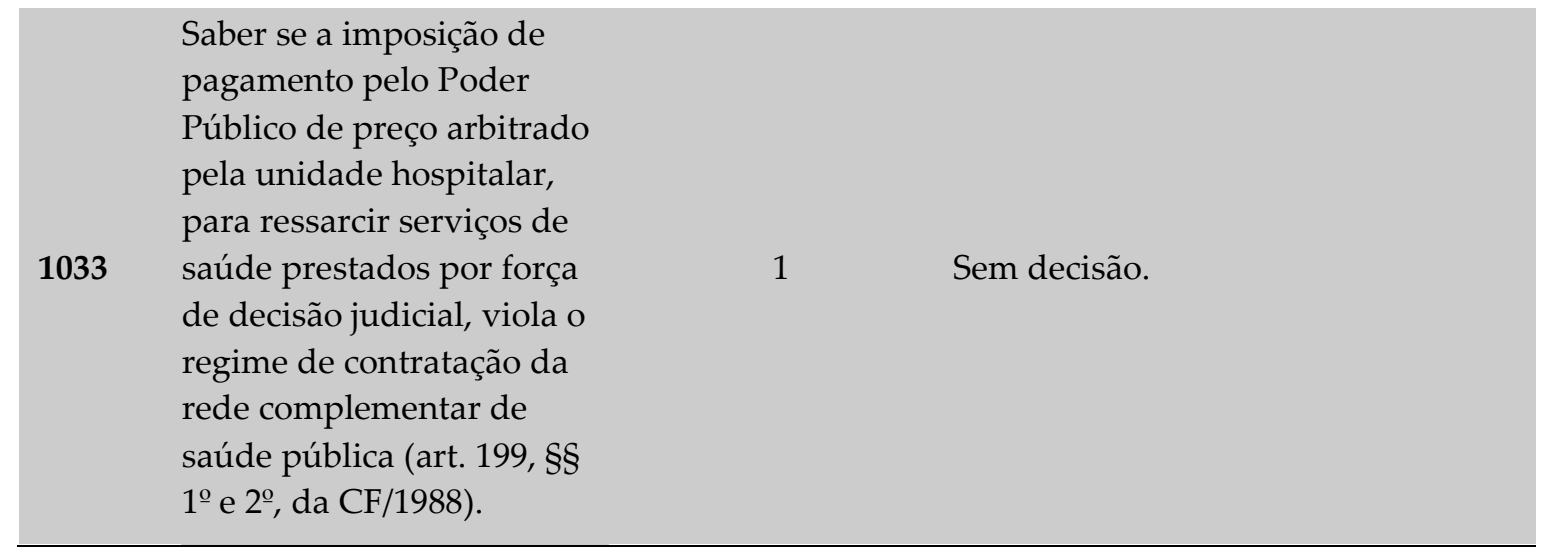

Fonte: Elaborado pela autora.

O tema 6, "Dever do Estado de fornecer medicamento de alto custo a portador de doença grave que não possui condições financeiras para comprá-lo", concentra a grande maior parte dos recursos sobrestados em saúde (27.316), seguido pela discussão sobre responsabilidade solidária (já julgado). Reconhecer a repercussão geral destes temas confere à Corte a oportunidade de estabelecer critérios de julgamento sistemáticos, aplicáveis a todos os casos a quo e possivelmente mais deferentes à política. Uma das críticas ao STA-175, por exemplo, era a sua difícil extensão para outros casos, já de decisão que no máximo serviria como indicativo de controle incidental e concreto de constitucionalidade, como improvável aplicação erga omnes. O julgamento destes temas, assim, poderia conduzir a Corte a um cenário de maior controle da jurisprudência $a$ quo.

A postura do STF até o momento, contudo, parece insistir na possibilidade de pretensões individuais direcionadas a qualquer ente público, desconsiderando a política em curso e sua organização, ou mesmo a avaliação técnica dos gestores. Como se pode observar na tese firmada para o tema 500, o sistema público pode ser condenado a oferecer tratamentos não aprovados pela ANVISA, bastando que o medicamento esteja registrado junto a uma agência internacional. Com essa posição, o STF demonstra sua não deferência ao processo administrativo de aprovação de novos medicamentos para consumo e comercialização nacional. $O$ tribunal, contudo, não indica que pontos deste processo precisariam ser avaliados e alterados para aprimorar a atuação da ANVISA como um todo, tampouco demonstra conhecer como outras agências internacionais atuam.

Os critérios de segurança necessários a aprovação de um produto perante o Food and Drug Admisntration (FDA), por exemplo, podem ser consideravelmente diferentes daqueles utilizados pela European Medicines Agency (EMA). Estes critérios são estabelecidos a partir do nível de evidência sobre segurança e efetividade que cada país está preparado para exigir de sua indústria farmacêutica levando em consideração o tempo limite que as agências dispõem para avaliar estas tecnologias. Em muitos casos, este nível pode ser baixo, sendo apenas necessário 
que as evidências sobre o produto apontem a sua segurança (não necessariamente sua efetividade) para ser comercializado.

O tribunal, ademais, demonstra não respeitar o processo de incorporação de novas tecnologias ao SUS, o qual não envolve apenas a aprovação do medicamento pela ANVISA, mas uma avaliação minuciosa e participativa realizada pela Comissão Nacional de Incorporação de Tecnologias do SUS ${ }^{19}$. Um medicamento pode ter sido aprovado pela ANVISA e, ainda assim, não ser adequado ao fornecimento público e gratuito pelo SUS por falta de custo-efetividade e pela presença de alternativas terapêuticas mais custo-efetivas.

No julgamento do tema 793, o tribunal indica que a organização federativa da política não precisa ser respeitada pelos litigantes. A responsabilidade solidária entre os três entes pelo provimento de serviços de saúde reafirma uma tese já consolidada pela Corte em outros julgados, de que todos os níveis da federação devem se responsabilizar pelo provimento de todos os tratamentos ofertados pelo SUS, mesmo que a política se organize respeitando as limitações administrativas e financeiras de cada ente.

Com essa tese, o tribunal mantém possível que um município pequeno, com orçamento restrito e com uma oferta de serviços desenhada às demandas epidemiológicas de sua população, seja obrigado a oferecer tratamentos caros ou complexos a alguns indivíduos, mesmo quando estes tratamentos já são de responsabilidade de outra secretaria ou da União Federal. O STF não oferece razões que justifiquem este posicionamento para além do direito à saúde como um argumento total (e individual). Tampouco leva a sério os argumentos apresentados pelos entes públicos, que tentam situar a demanda individual que chega às Cortes em um panorama maior de organização da política, a qual envolve o provimento de serviços a todos os demais usuários do SUS, de acordo com as diferentes capacidades de cada órgão do sistema.

\section{A solução do problema: as respostas do CNJ}

Se o STF como tribunal dá preferência a uma visão individualista das demandas de saúde, é o seu braço administrativo, o CNJ, que se volta a dimensão estrutural e coletiva do tema. Uma das consequências da audiência de 2009 é a atuação crescente do órgão sobre o tema da saúde púbica ${ }^{20}$. Um grupo de trabalho instituído em março de 2010 pelo CNJ após a audiência gerou um conjunto de recomendações à juízes para a análise de ações em saúde: a Recomendação CNJ n. 31/2010. Esta norma incorpora muitos dos pontos da audiência pública e vai além. Mais do que incentivar que juízes sejam deferentes a política de saúde e incorporem argumentos

\footnotetext{
19 Processo esse que foi criado como uma resposta administrativa à judicialização. Para mais informações sobre esta resposta institucional conferir: Wang (2015).

${ }^{20}$ Cf. Wang (2015), Vasconcelos (2018), Brasil (2017a) e Do Valle e Camargo (2011).
} 
técnicos em suas decisões ${ }^{21}$, o CNJ passou a recomendar que tribunais estaduais e federais criassem estruturas próprias de diálogo e assistência a juízes em temas de direito sanitário.

A recomendação de 2010 aconselhava tribunais a estabelecer convênios para a oferta de apoio técnico de médicos e farmacêuticos, de modo a apreciar as questões clínicas trazidas pelas ações e a peculiaridades regionais da saúde. Ademais, a Recomendação ainda aconselhava a incorporação de direito sanitário em cursos de formação e entre os temas de concursos públicos da magistratura. Com a recomendação foi criado, ainda, o Fórum da Saúde do Judiciário (BRASIL, 2010), constituído por um Comitê Executivo Nacional e comitês estaduais ${ }^{22}$. O Fórum é responsável pelo monitoramento de ações judiciais em saúde, tanto em relação à concessão específica de medicamentos, insumos ou serviços e leitos hospitalares como qualquer outra ação judicial contra a gestão do SUS. Por meio desse monitoramento, o Fórum se estabelece como um espaço de proposição de medidas concretas e normativas para a "otimização de rotinas processuais, a organização e estruturação de unidades judiciárias especializadas", bem como para a "proposição de medidas concretas e normativas voltadas à prevenção de conflitos judiciais e à definição de estratégias nas questões de direito sanitário" 23 .

O Fórum se submete à supervisão do plenário do $\mathrm{CNJ}$, que é presidido pelo presidente do STF, e é integrado por magistrados e membros do Conselho Nacional do Ministério Público, do Ministério Público Federal, dos governos estaduais, Defensorias Públicas, Ordem dos Advogados do Brasil e de universidades e instituições de pesquisa. No âmbito da atuação do Fórum, cujo primeiro encontro ocorreu em novembro de 2010, foram promovidas três Jornadas da Saúde em 2014, 2015 e 2019. O Comitê Nacional do Fórum é composto formalmente, em sua maioria, por membros do Judiciário, formato encontrado em todas as suas composições, desde a original de 2010 até suas alterações em 2011, 2012 e $2014^{24}$.

\footnotetext{
${ }^{21}$ Por exemplo, a recomendação aconselhava juízes e cortes a procurar uma melhor instrução das ações a partir de relatórios médicos com descrição da doença, CID e prescrição de medicamentos, com denominação genérica ou princípio ativo com posologia exata; a evitar a autorização de fornecimento de medicamentos ainda não registrados pela ANVISA, ou em fase experimental; e a ouvir, quando possível e preferencialmente por meio eletrônico, os gestores, antes da apreciação de medidas de urgência. Não somente, recomendava que juízes exijam a inscrição dos demandantes em programas já oferecidos pelo sistema público.

${ }^{22}$ Para uma análise mais detalhada das atividades do Fórum e seus desdobramentos, conferir TULLII, Marcela Silveira. Para Além Da Judicialização: Política Pública Da Justiça No Campo Da Saúde. Dissertação de Mestrado apresentada ao Programa de Pós-Graduação em Ciência Política da Faculdade de Filosofia, Letras e Ciências Humanas, Universidade de São Paulo. São Paulo: 2017.

${ }^{23}$ Cf. nota 35.

${ }^{24}$ Conferir as diferentes portarias CNJ que alteram a composição do Comitê: Brasil (2010; 2011; 2012; 2014).
} 
Os membros dos Comitês estaduais também eram designados pelo CNJ, mas, desde 2016 têm as indicações realizadas pela presidência dos tribunais, de preferência dentre os magistrados que exerçam jurisdição em temas de saúde (BRASIL, 2016a). Os Comitês estaduais não só devem contar com rol mínimo de membros permanentes designados em meio a magistratura local - juízes de primeiro e segundo grau, das justiças estadual e federal, como também gestores da área da saúde de todas as esferas - federal, estadual e municipal, participantes da ANVISA, ANS e CONITEC, Ministério Público Federal e Estadual, Defensoria Pública, advogados públicos ou representante da $\mathrm{OAB}$ e representantes dos usuários do sistema público, indicado pelo Conselho estadual de saúde, e do sistema privado, indicados pelos Procons de cada estado.

Outra das recomendações que se traduziu em criação institucional foi a expansão dos Núcleos de Apoio Técnico do Judiciário (NAT-JUS). Constituídos por profissionais da saúde, estes núcleos foram idealizados como estruturas de apoio a magistrados, que emitiriam pareceres para auxílio técnico a juízes caso-a-caso, desde que os magistrados recorressem a equipe técnica (ou seja, a utilização dos NATs pelos magistrados é voluntária). Tais pareceres devem ser elaborados a partir da medicina baseada em evidências e o seu conjunto é organizado atualmente para compor um banco de dados nacional de acesso a todos os tribunais e juízes, o "ENATJUS".

A consolidação do próprio $\mathrm{CNJ}$ como uma instituição do STF de gestão dos serviços de justiça como um todo se traduziu, no caso da saúde, em uma maior obrigatoriedade das "recomendações" de 2010, que logo passaram a ser formuladas em resoluções posteriores como "exigências" às justiças pelo país. O nível de implementação das medidas, contudo, varia de Estado para Estado, já que o CNJ não se responsabiliza pela organização ou financiamento destas inciativas.

Assim, se os Comitês foram desenhados inicialmente como um fórum de encontro de diferentes instituições da gestão da saúde e do sistema de justiça (os Comitês podem convidar participantes externos para as suas reuniões), eles não são estruturados de maneira uniforme entre os Estados e tem participação variada mesmo dos membros permanentes, uma vez que a presença nas reuniões é voluntária para a maior parte das instituições (VASCONCELOS, 2018; TULLII, 2017). Vasconcelos (2018) indicia a baixa participação, por exemplo, de membros da categoria médica ou da $\mathrm{OAB}$, além de constatar que para a maior parte dos Comitês instituídos, os atores que efetivamente participam das reuniões especialmente entre os magistrados - já seriam "convertidos", enxergando a judicialização como uma "questão/problema" que exigiria respostas institucionais deliberadas entre instituições.

No caso dos NATs, por exemplo, sua implementação assume variações significativas de Estado a Estado. No caso do Rio de Janeiro, por exemplo, o NAT não só funciona dentro dos prédios das duas Justiças (Estadual e Federal), mas também opera um grupo grande de funcionários em regime de plantão, e tem 
atuação que cobre quase todo o Estado. Em Santa Catarina, uma experiência mais recente que a do Rio de Janeiro, o NAT é dotado de uma estrutura e orçamento menor, operando completamente no prédio da Secretaria Estadual de Saúde. Não somente, o núcleo divide seu tempo de elaboração de pareceres com a alimentação de um banco de dados acessível a juízes e outros membros do sistema de justiça estadual. Em São Paulo, de outro lado, o NAT foi criado especificamente para auxílio em demandadas da saúde suplementar, em parceria com Agência Nacional de Saúde Suplementar, Associação Brasileira de Medicina de Grupo e Federação Nacional de Saúde Suplementar, e tem baixa adesão dos juízes, de modo que desde a sua criação emitiu poucos pareceres (VASCONCELOS, 2018) ${ }^{25}$.

Tal como a variação dos NATs entre Estados, a própria implementação mais abrangente de todas as medidas exigidas pelo CNJ em suas resoluções enfrenta variações. De acordo com relatório do Tribunal de Contas da União, por exemplo, a maioria dos tribunais analisados não havia adotado as medidas preconizadas pelo CNJ até 2015. Na justiça federal, o TCU não identificou a implementação completa de convênios entre os Tribunais Regionais Federais e as instâncias de apoio técnico médico e farmacêutico. Na justiça estadual, até 2015, o TCU apenas identificou NATs criados em Minas Gerais, Santa Catarina, Mato Grosso e Rio de Janeiro, e desde 2015 identifiquei a criação apenas de 7 outros NATs (VASCONCELOS, 2018) ${ }^{26}$.

\begin{tabular}{|c|c|c|}
\hline ESTADO & $\begin{array}{c}\text { ANO DE } \\
\text { CRIAÇÃO }\end{array}$ & $\begin{array}{c}\text { ÂMBITO DE } \\
\text { ATUAÇÃO }\end{array}$ \\
\hline RJ & 2009 & saúde pública \\
\hline SC & 2015 & saúde pública \\
\hline SP & 2015 & saúde suplementar \\
\hline MG & 2012 & saúde pública \\
\hline GO & 2011 & saúde pública \\
\hline PR & 2013 & $\begin{array}{l}\text { saúde pública e } \\
\text { suplementar }\end{array}$ \\
\hline TO & 2013 & saúde pública \\
\hline MT & 2011 & saúde pública \\
\hline AP & 2016 & $\begin{array}{l}\text { saúde pública e } \\
\text { suplementar }\end{array}$ \\
\hline $\mathrm{AC}$ & 2017 & saúde pública \\
\hline
\end{tabular}

\footnotetext{
${ }^{25}$ Este cenário, contudo, vêm sendo alterado desde a criação do Comitê Estadual da Saúde no Estado e da adesão ao e-NAT Jus. Um acompanhamento mais atual deste novo cenário não foi realizado ainda por trabalhos acadêmicos.

${ }^{26}$ Informações extraídas do banco de notícias eletrônicas do $\mathrm{CNJ}$, uma vez que o próprio CNJ não disponibiliza esta informação de maneira sistematizada para consulta online.
} 
CE $\quad 2016 \quad$ saúde pública

Fonte: Vasconcelos (2018)

A especialização de varas e seções judiciárias e a inclusão do direito sanitário em concursos ou na formação de juízes também encontra baixa adesão pelos tribunais. As escolas federais dos TRF1, TRF2 e TRF3 incorporaram o direito sanitário em seus cursos de formação, mas esta medida só teve a adesão de cinco escolas estaduais - AP, MG, MT PR, SC. O TJRS especializou a 10aㅡ Vara da Fazenda Pública e seu Juizado Especial nas ações de saúde, o TRF4 implantou varas especializadas nas cidades de Curitiba e Porto Alegre, e a Justiça Federal do Rio de Janeiro implantou varas especializadas em saúde no ano de $2017-4^{\underline{a}}, 15^{\underline{a}}, 23^{\underline{a}}, 28^{\underline{a}}$ Vara Federais (BRASIL, 2017a; VASCONCELOS, 2018) ${ }^{27}$.

Comitês estaduais, NATs e varas especializadas demonstram que o CNJ busca alterar estruturalmente a atuação de juízes e tribunais para que estes se tornem mais sensíveis à política de saúde, tanto em sua dimensão técnica como coletiva. Estas medidas, contudo, enfrentam tanto problemas ligados a fragmentação administrativa do Judiciário como as limitações da própria atuação administrativa e não jurisdicional do CNJ. De um lado, o CNJ tenta reestruturar de forma centralizada a gestão destas demandas, inserido novos espaços e atores no processo de tomada de decisão de juízes em busca de uma atuação mais especializada do Judiciário sobre estas demandas. O órgão, contudo, não tem capacidade jurisdicional, de modo que trazer mais evidências e especializar varas não necessariamente altera o resultado das demandas. Juízes podem ter mais incentivos para trazer argumentos mais "técnicos" e menos "jurídicos" a sua argumentação, mas não estão obrigados a tanto: seu livre convencimento seria apenas restringido se as Cortes superiores estabelecessem precedentes obrigatórios, que reformariam decisões a quo e, assim, reeducariam juízes mesmo quando não dispostos a tomar decisões difíceis.

De outro lado, o CNJ tenta trazer o SUS para dentro do Judiciário e permitir que juízes atuem já no processo de formulação da política de saúde. Diante da certeza de que as demandas irão ser judicializadas de qualquer jeito, o órgão então tenta combater a judicialização inserindo a perspectiva do sistema de justiça já no início da política. Os Comitês estaduais e o Fórum Nacional da Saúde se tornam espaços em que juízes não só se educam sobre a política, mas "educam" gestores sobre as demandas judicializadas. Gestores e juízes, contudo, não participam desses fóruns em posições equivalentes. Ainda que gestores sejam guardiões da dimensão "técnica" do problema, ao fim e ao cabo, serão obrigados a cumprir a interpretação judicial, enquanto esta não tem a obrigação de levar em conta a técnica.

27 Conferir lista completa de lotações de juízes federais da $2^{\underline{a}}$ região. Disponível em: https://www10.trf2.jus.br/corregedoria/wp-content/uploads/sites/41/2015/11/lista-completalotacoes-juizes-federais-2a-regiao.pdf. 


\section{CONCLUSÃO: SOLUÇÃO DO PROBLEMA E PROBLEMA DA SOLUÇÃO}

A descrição acima indica que o STF tem duas posições aparentemente contraditórias sobre o "problema" da judicialização da saúde. De um lado, a Corte se comporta como todas as demais instâncias decisórias, sendo extremamente favorável a concessão judicial de tratamentos e insumos sem oferecer aos tribunais a quo ou à própria política balizas concretas sobre o que deve ser ofertado, quando e o que pode ser concedido judicialmente.

Ao permitir que juízes decidam caso a caso o que é adequado, mesmo se o tratamento não tiver sido incorporado ao SUS ou mesmo aprovado pela ANVISA, e ao decidir que não avalia "matéria de prova" ou os critérios específicos da política em suas nuances - por exemplo, quem provê assistência farmacêutica, quem a financia, que programas estão disponíveis, como o SUS incorpora novas tecnologias e revisa seus protocolos cínicos, etc. - a Corte simplesmente se abstém de decidir casos difíceis e indica que o direito constitucional a saúde é, para o Judiciário, uma pretensão individual que transcende qualquer política pública e, assim, a dimensão coletiva do direito à saúde. A ausência de decisões estruturais, mesmo em temas considerados de repercussão geral, permite que STF atue sem aparentemente comprometer sua legitimidade. Afinal, no caso a caso os ministros não aparecem decidindo política ou realocando recursos, mas apenas garantindo direitos. Ao endossar essa posição também dos demais tribunais, sua jurisprudência contribui para a judicialização e aprofunda o problema - juízes e tribunais não têm incentivos para reformar suas posições institucionalmente favoráveis a demandas individuais, já que decisões assim serão potencialmente reformadas pela Corte em sede de recurso ${ }^{28}$.

Ao rejeitar casos que discutem evidências, ademais, a Corte evita por em questão sua capacidade institucional para lidar com temas de saúde. A audiência pública de 2009, que deveria ter funcionado como um espaço de aprendizado técnico aos ministros, recebe poucas referências na própria jurisprudência do STF. Ela, contudo, abriu caminhos para uma intervenção mais sistemática da Corte por seu braço administrativo. Se o STF não pode ou não quer resolver o problema como Corte, escolhe tentar fazê-lo como gestor da política pública de justiça via CNJ. Esta solução para o problema, contudo, é repleta de problemas.

\footnotetext{
${ }^{28}$ Um espaço possível de reversão dessas tendências é o STJ. Este artigo não se volta a sua massiva jurisprudência em saúde, mas ressalto que este é um fórum que também elegeu temas de saúde pública como casos paradigmáticos em incidentes de recursos repetitivos e merece uma agenda de pesquisa própria, especialmente no que tange a interação dos recursos especiais e sua possível contestação junto ao STF.
} 
Em primeiro lugar, o CNJ não é um órgão jurisdicional. Enfrenta problemas em vincular todos os juízes e tribunais a suas normativas, que se tornam paulatinamente menos parecidas com recomendações e mais com exigências, em uma tentativa de impor alguma forma de constrangimento as todas as demais instâncias da justiça. Ademais, se estas exigências atuam substantivamente sobre o processo decisório, como parece ser o intuito das medidas até então implementadas pelo órgão, juízes têm sempre ao seu lado a garantia de independência funcional que, assim, apoia suas pretensões de livre convencimento.

Capacitar tecnicamente tribunais para lidar com demandas de direito sanitário, contudo, não substitui a própria política e, impreterivelmente, juízes vão ser menos treinados que gestores para tomar decisões técnicas ou para realizar escolhas trágicas. Se medidas como os NATs e Comitês possuem o condão de aproximar magistrados do direito sanitário, estas estruturas não substituem os conselhos de saúde e todas as instâncias administrativas que compõem o SUS. Mais ainda, são medidas dotadas da autoridade não democrática do Judiciário, enquanto as decisões do SUS são concebidas em geral em processo decisório altamente responsivo à sociedade civil.

Além destas limitações em termos de eficiência e legitimidade, o problema da solução ainda é mais profundo: enquanto vemos um Judiciário financiar o crescimento de sua estrutura administrativa para dialogar e resolver questões que envolvem saúde pública, tem-se o trágico cenário de um SUS subfinanciado. Ao fim e ao cabo, a escolha continua a ser trágica e desfavorável a pretensões coletivas - a Justiça gasta recursos para tentar decidir melhor questões de saúde e, inclusive, substituir o SUS como decisor final em pretensões individuais, mas não substitui a política organizada.

Esta, contudo, sofre com a crônica falta de investimentos, especialmente sob governos recentes. Os recursos humanos e financeiros que são transferidos do SUS a estas estruturas judiciais - os gestores que são alocados a trabalhar nos NATs ou atuar nos Comitês, as equipes de informática, espaços físicos e recursos financeiros voltados a "gestão da judicialização" retiram do Estado, impreterivelmente, meios de prover o serviço fim da política de saúde. Tem-se, então, uma solução que não só tem problemas, mas que pode causar novas ineficiências ao sistema.

\section{REFERÊNCIAS}

BRASIL. Conselho Nacional de Justiça. Judicialização da Saúde no Brasil: Perfil das Demandas, Causas e Propostas de Solução, Brasília, 2019a. Disponível em: http://www.cnj.jus.br/files/conteudo/arquivo/2019/03/95da70941b7cd226f9835d56 017d08f4.pdf. Acesso em: 25 jun. 2019. 
BRASIL. Conselho Nacional de Justiça. Resolução n. 238, Atos Normativos, 06 de setembro de 2016a.

BRASIL. Conselho Nacional de Justiça. Portaria n. 91, Atos Normativos, 30 de junho de 2011.

BRASIL. Conselho Nacional de Justiça. Portaria n. 58, Atos Normativos, 11 de maio de 2010.

BRASIL. Conselho Nacional de Justiça. Portaria n. 69, Atos Normativos, 22 de maio de 2012.

BRASIL. Conselho Nacional de Justiça. Portaria n. 40, Atos Normativos, 25 de março de 2014.

BRASIL. Conselho Nacional de Justiça. Resolução n. 107, Atos Normativos, 06 de abril de 2010.

BRASIL. Tribunal de Contas da União. Acórdão 1787, Plenário, Processo n. 009.253/2015-7. Biblioteca Digital, 16 de agosto de 2017a. Disponível em https://portal.tcu.gov.br/biblioteca-digital/auditoria-operacional-sobrejudicializacao-da-saude.htm. Acesso em: 25 jun. 2019.

BRASIL. Supremo Tribunal Federal. Petição 1246 MC, Rel. min. Celso de Melo, Pesquisa de Jurisprudência, Acórdãos, 31 de janeiro de 1997.

BRASIL. Supremo Tribunal Federal. Medida Cautelar na Ação Descumprimento de Preceito Fundamental n. 45, Pesquisa de Jurisprudência, Acórdãos, 29 de abril de 2004.

BRASIL. Supremo Tribunal Federal. Suspensão de Tutela Antecipada n. 91, Rel. min. Ellen Gracie. Pesquisa de Jurisprudência, Acórdãos, 26 de fevereiro de 2007a.

BRASIL. Supremo Tribunal Federal. Suspensão de Segurança n. 3073, Rel. min. Ellen Gracie, Pesquisa de Jurisprudência, Acórdãos, 09 de fevereiro de 2007b.

BRASIL. Supremo Tribunal Federal. Supremo Tribunal Federal, SS 3263, Rel. min. Ellen Gracie. Pesquisa de Jurisprudência, Acórdãos, 23 de julho de 2007c. 
BRASIL. Supremo Tribunal Federal. Agravo de Instrumento n. 618943/RS, Rel. min. Menezes Direito. Pesquisa de Jurisprudência, Acórdãos, 19 de maio de 2008a.

BRASIL. Supremo Tribunal Federal. Agravo de Instrumento n. 597141/RS, Rel. min. Carmen Lucia. Acórdãos, 11 de junho de 2007d.

BRASIL. Supremo Tribunal Federal. Agravo de Instrumento n. 696511/RS, Rel. min. Ellen Gracie. Acórdãos, 22 de outubro de 2008b.

BRASIL. Supremo Tribunal Federal. Recurso Extraordinário n. 575631/RS, Rel. min. Carlos Britto. Pesquisa de Jurisprudência, Acórdãos, 31 de outubro de 2008c.

BRASIL. Supremo Tribunal Federal. Recurso Extraordinário n. 563954/RS, Rel. min. Eros Grau. Pesquisa de Jurisprudência, Acórdãos, 12 de março de 2008d.

BRASIL. Supremo Tribunal Federal. Agravo de Instrumento n. 717243/RS, Rel. min. Celso de Mello. Pesquisa de Jurisprudência, Acórdãos, 12 de junho de 2008e.

BRASIL. Supremo Tribunal Federal. Recurso Extraordinário n. 573948/RS, Rel. min. Cezar Peluso. Pesquisa de Jurisprudência, Acórdãos, 22 de fevereiro de 2008f.

BRASIL. Supremo Tribunal Federal. Agravo de Instrumento n. 714280/RS, Rel. min. Celso de Mello. Pesquisa de Jurisprudência, Acórdãos, 03 de junho de 2008g.

BRASIL. Supremo Tribunal Federal. Recurso Extraordinário n. 579758/RS, Rel. min. Cezar Peluso. Pesquisa de Jurisprudência, Acórdãos, 04 de março de 2008h.

BRASIL. Supremo Tribunal Federal. Agravo de Instrumento no $¹ 7243 / R S$, Rel. min. Celso de Mello. Pesquisa de Jurisprudência, Acórdãos, 12 jun. 2008 i.

BRASIL. Supremo Tribunal Federal. Recurso Extraordinário no 573948/RS, Rel. min. Cezar Peluso. Pesquisa de Jurisprudência, Acórdãos, 22 fev. 2008j.

BRASIL. Supremo Tribunal Federal. Audiência Pública n. 4. Processos, Audiências Publicas, 27, 28 e 29 de abril de 2009. Disponível em: http://www.stf.jus.br/portal/cms/verTexto.asp?servico=processoAudienciaPublica Saude. Acesso em: 25 jun. 2019. 
BRASIL. Supremo Tribunal Federal. Suspensão de Tutela Antecipada n. 175, Rel. min. Gilmar Mendes. Pesquisa de Jurisprudência, Acórdãos, 17 de março de 2010a.

BRASIL. Supremo Tribunal Federal. Agravo no Recurso Extraordinário n. 956960/RS, Rel. min. Roberto Barroso. Pesquisa de Jurisprudência, Acórdãos, 05 de abril de 2016b.

BRASIL. Supremo Tribunal Federal. Recurso Extraordinário n. 1019536/RJ, Rel. min Gilmar Mendes. Pesquisa de Jurisprudência, Acórdãos, 27 de março de 2019b.

BRASIL. Supremo Tribunal Federal. ARE 933183/DF, Rel. min. Alexandre de Moares. Pesquisa de Jurisprudência, Acórdãos, 04 de março de 2018a.

BRASIL. Supremo Tribunal Federal. ARE 1038202 AgR/RJ, Rel. min. Gilmar Mendes. Pesquisa de Jurisprudência, Acórdãos, 20 de fevereiro de 2018b.

BRASIL. Supremo Tribunal Federal. ARE 1049831 AgR/PE, Rel. min. Edson Fachin. Pesquisa de Jurisprudência, Acórdãos, 27 de outubro de 2017b.

BRASIL. Supremo Tribunal Federal. RE 575179 AgR/ES, Rel. min. Dias Toffoli. Pesquisa de Jurisprudência, Acórdãos, 26 de fevereiro de 2013.

DO VALLE, Gustavo Henrique Moreira, CAMARGO, João Marcos Pires. A audiência pública sobre a judicialização da saúde e seus reflexos na jurisprudência do supremo tribunal federal, Revista de Direito Sanitário, v. 11, n. 3, p. 13-31, 2011.

CHIEFFI, Ana Luiza, BARATA, Rita Barradas. Judicialização da política pública de assistência farmacêutica e equidade. Cad. Saúde Pública, Rio de Janeiro, v. 25, n.8, p. 1839-1849, 2009;

FERRAZ, O. L. M., The right to health in the courts of Brazil: Worsening health inequalities? Health and Human Rights: An International Journal, vol. 11, n. 2, 2009 , p. 33-45.

FERRAZ, Octavio Luiz Motta, VIEIRA, Fabiola Sulpino. Direito à proteção da saúde, recursos escassos e equidade: os riscos da interpretação judicial dominante. Dados Revista de Ciências Sociais, vol. 52, n.1, 2009, p. 223-251. 
FERREIRA, Camila Duran et al. Atuação do judiciário na concretização dos direitos sociais: Um estudo empírico do reconhecimento do direito à saúde como direito fundamental. In: Prêmio IPEA 40 anos: monografias premiadas. Brasília: IPEA, 2005.

GLOPPEN, Siri, ROSEMAN, Mindy Jane. "Introduction: Can litigation bring justice to health?". In: GLOPPEN, S. e YAMIN, A.E., Litigating Health Rights. Cambridge: Harvard University Press, 2011, p. 1-16.

GOMES, Dalila F. et al. Judicialização da saúde e a audiência pública convocada pelo Supremo Tribunal Federal em 2009: o que mudou de lá para cá? Saúde em Debate, n. 38, v. 100, 2014, p. 139-156.

LAMPREA MONTEALEGRE, Everaldo. Derechos en la práctica: jueces, litigantes y operadores de políticas de salud en Colombia (1991-2014). Ediciones UniandesUniversidad de los Andes, 2015.

MARQUES, Rosa Maria, Notas Exploratórias sobres as Razões do Subfinanciamento do SUS, Planejamento e Políticas Públicas n. 49, Brasília: Ipea, 2017.

OLIVEIRA, Vanessa Elias de; MARCHETTI, Vitor. O Judiciário e o controle sobre as políticas públicas: a judicialização da educação no município de São Paulo. Artigo apresentado no 37 Encontro Nacional da Anpocs, Caxambu, MG, 2013.

PIOLA, Sergio, PAIVA, Andrea, SÁ, Edvaldo, SERVO, Luciana. Financiamento Público da Saúde: uma história a procura de rumo. Texto para Discussão, Ipea. Brasília: Rio de Janeiro: Ipea, 2013;

SANTOS, Alethele de Oliveira, DELDUQUE, Maria Célia, \& MENDONÇA, Ana Valéria Machado. Os discursos na Audiência Pública da Saúde e seu impacto nas decisões do Supremo Tribunal Federal: uma análise à luz da teoria dos sistemas sociais. Saúde e Sociedade, 24, (1), p.184-192, 2015.

TAYLOR, Matthew M. O judiciário e as políticas públicas no Brasil. DADOSRevista de ciências sociais, v. 50, n. 2, 2007.

TULLII, Marcela Silveira. Para Além Da Judicialização: Política Pública Da Justiça No Campo Da Saúde. Dissertação de Mestrado apresentada ao Programa de Pós- 
Graduação em Ciência Política da Faculdade de Filosofia, Letras e Ciências Humanas, Universidade de São Paulo. São Paulo: Universidade de São Paulo, 2017.

VASCONCELOS, Natalia Pires de, Mandado de Segurança ou Ministério da Saúde. Tese (Doutorado em Direito do Estado), Faculdade de Direito, São Paulo: Universidade de São Paulo, 2018.

WANG, Daniel, Right to Health litigation in Brazil: The problem and the institutional responses. Human Rights Law Review, v. 15, n. 4, p. 617-641, 2015;

WANG, Daniel. Poder Judiciário e participação democrática nas políticas públicas de saúde. 2009. Dissertação (Mestrado em Direito do Estado), Faculdade de Direito, São Paulo: Universidade de São Paulo, 2009.

WANG, Daniel; TERRAZAS, Fernanda. Decisões da Ministra Ellen Gracie sobre medicamentos. Texto para Discussão. Sociedade Brasileira de Direito Público, 2007.

WANG, Daniel et al. Os impactos da judicialização da saúde no município de São Paulo: gasto público e organização federativa. Revista de Administração PúblicaRAP, v. 48, n. 5, 2014.

YAMIN, Alicia Ely; PARRA-VERA, Oscar; GIANELLA, Camila. Judicial Protection of the Right to Health: An Elusive Promise? In: GLOPPEN, S.; YAMIN, A.E. Litigating Health Rights. Cambridge: Harvard University Press, 2011. 